\title{
HILDA HILST: DOIS POEMAS, DUAS VERSÕES
}

\author{
Beatriz Cabral Bastos
}

O início deste trabalho se deu em 2002, num workshop de tradução poética na SOAS (School of Oriental and African Studies) em Londres. Embora acontecesse na faculdade, ele não fazia parte de nenhum curso regular, e era aberto para qualquer pessoa que desejasse traduzir para o inglês poesias escritas em outras línguas. Interessada por poesia, e interessada por tradução, levei ao grupo algumas versões um tanto literais de alguns poemas da poeta Hilda Hilst - apresentar uma primeira versão "literal" era a primeira fase do processo de tradução nesse grupo - e decidiram trabalhar com um dos poemas que apresento neste trabalho. Embora o resultado final da versão feita pelo grupo não seja totalmente insatisfatório, percebi que deixamos de lado aspectos importantes do poema, pois estávamos limitados a uma tradução preocupada unicamente com o sentido, não atentando em momento algum ao ritmo e às rimas, que sem que nós soubéssemos, eram em grande parte responsáveis pela musicalidade e beleza desta poesia.

Com o intuito de fazer versões cuidadosas de dois poemas de Hilda Hilst, o primeiro passo foi fazer a escansão de cada poema, para mostrar o ritmo e as rimas presentes nos poemas originais em português. Abordamos também aspectos sintáticos dos poemas: repetições, inversões, quando esses parecem produzir algum efeito específico, relevantes para a tradução. É certo que esses se cruzam com os aspectos semânticos do poema, com seu tipo de dicção, com o tipo de vocabulário usado, e com algumas imagens poéticas que são particularmente interessantes, e difíceis, de traduzir. Analisamos as duas versões propostas para o inglês, demonstrando quais níveis de correspondência foram mantidos.

Os dois poemas escolhidos fazem parte do livro Júbilo, Memória, Noviciado da Paixão, publicado pela primeira vez em 1974. De acordo com Nelly Novaes Coelho, comentador da obra de Hilda Hilst, este livro é o primeiro de uma fase em que a autora retorna à poesia, após um período dedicado à produção ficcional e teatral. É uma poesia 
bastante musical, onde quase podemos ouvir a poeta tocando a sua lira - ou bandolim, como indica o título de uma parte do livro, enquanto através da poesia evoca, ou seduz, ou indaga o ser amado, que recebe nomes múltiplos como "Dionísio”, “Túlio”, ou simplesmente "amigo". Em entrevista, a autora concorda que enquanto sua obra de ficção encontra maiores afinidades com a prosa moderna, sua poesia parece estar filiada a uma tradição mais antiga. Remete simultaneamente ao universo das cantigas de amigo (“Chamamentos ao amigo” é o título de outra das subpartes) e a um mundo ainda mais distante, o grego, de Dionísio. São poemas sensuais, embora apenas em poucos momentos marcadamente eróticos, como acontece em outras partes da obra da autora.

Hilda Hilst já teve parte de sua obra traduzida. Em francês, encontramos L'obscène madame D suivit de le chien, uma obra em prosa, e Da Morte/Odes Mínimas, poesia, publicada em edição bilíngüe. Em italiano, temos Il quaderno rosa di Lori Lamby, também em prosa. Que se saiba, não existem traduções publicadas de sua poesia para o inglês, embora seja possível encontrar espalhadas pela internet, em blogs pessoais, algumas versões.

\section{Poema 1 \\ (original em português)}

Essa lua enlutada, esse desassossego

A convulsão de dentro, ilharga

Dentro da solidão, corpo morrendo

Tudo isso te devo. E eram tão vastas

As coisas planejadas, navios,

Muralhas de marfim, palavras largas

Consentimento sempre. E seria dezembro.

Um cavalo de jade sob as águas

Dupla transparência, fio suspenso

Todas essas coisas na ponta dos teus dedos

E tudo se desfez no pórtico do tempo

Em lívido silêncio. Umas manhãs de vidro

Vento, a alma esvaziada, um sol que não vejo.

Também isso te devo.

Examinando a forma do poema cujo primeiro verso é "Essa lua enlutada" encontramos 14 versos, embora se trate de algo diferente de um soneto (ver anexo 1). Uma característica marcante são as cesuras presentes em todos os versos, exceto no último. O número de acentos em cada hemistíquio varia bastante, com uma média de dois acentos primários em cada. Os versos são longos se comparados com os versos do 
poema que analisaremos em seguida, e podemos falar de um enjambement entre os versos 4 e 5. Observamos ainda a presença de algumas aliterações ("lua enlutada/ muralhas de marfim”). Além disso, pode-se notar, embora o poema esteja escrito na primeira pessoa, que o pronome pessoal oblíquo da segunda pessoa é o mais marcado: “te devo” aparece logo no começo do poema, e depois é repetido no final, e o uso de "teus dedos", no verso 10, enfatiza ainda mais a segunda pessoa. Outro elemento repetido algumas vezes são os pronomes demonstrativos “essa”, “esse”, que pela força do contraste aumenta a estranheza do uso do artigo indefinido em "umas manhãs".

Porém, é o esquema de rimas internas com rimas externas o que estruturalmente mais chama atenção neste poema. São todas rimas toantes, onde a letra $a$ corresponde à rima toante em /a_a/ que acontece entre “enlutada”, “ilharga” , “vastas”, “planejadas” etc., e a letra $b$ corresponde à rima em /e/ de “desassosego", “dentro”, “morrendo". Como podemos notar, a alternância entre estes dois sons nos finais dos hemistíquios ou ao final dos versos é bastante constante e estável em todo o poema. Embora possamos mencionar ainda uma outra rima (c), com o /i/ presente em "navio", "marfim” e "vidro".

Na tradução desse poema, desejamos preservar os efeitos poéticos que são mais regulares no original e portanto, nosso principal objetivo será manter o esquema de rimas. Uma análise semântica, palavra por palavra, assim como uma análise sintática mais detalhada, poderiam estar incluídas no nosso quadro de análise. Mas tendo em vista que o nosso interesse é a tradução destes versos para o inglês, faremos mais adiante uma análise apenas dos momentos em que não foi possível uma tradução literal, ou quase literal. Por isso, antes de comentarmos com mais cuidado os aspectos semânticos, combinados com questões sintáticas dos versos, leremos a versão em inglês e analisaremos a qualidade da correspondência formal.

\section{Poema 1 \\ (versão para o inglês)}

This mournful moon, this unease Inner turbulence, lagoon, Inside of solitude, a dying body, All this I owe you. Such immense Plans and future, ships, Walls of ivory, words full Always consented to. It would be December.

A jade horse beneath the waters Double transparency, a line in mid-air All these things at your fingertips 
All undone through the portal of time

Silent and blue. Some mornings of glass,

Wind, a hollow soul, a sun I can't see

This, too, I owe you.

Vejamos agora o esquema de rimas na versão em inglês (ver anexo 2). Como podemos notar, uma correspondência com o esquema de rimas do original foi mantida, embora de forma mais fraca. Estabelecendo como rima "a" as palavras que rimam com "moon", "solitude" e "full", e como rima "b" as palavras terminadas em sons sibilantes, como em "unease”, em "turbulence” e em“ immense”. Foram mantidas também as cesuras nos versos, e o enjambement presente no original em português também está presente na versão em inglês. Quanto às aliterações, elas estão presentes, embora nem sempre nos mesmos versos. A ênfase nos pronomes da segunda pessoa do singular também foi mantida, e onde ele é repetido em português, ele também é repetido em inglês.

Passemos agora a uma análise mais lexical e semântica da versão, onde tentarei explicitar os motivos de certas escolhas, e até que ponto foram ou não bem-sucedidas.

"Desassossego", no primeiro verso é uma palavra marcadamente poética em português, que nos remete a Fernando Pessoa, cuja versão para "unease” não preserva a dicção poética do original. Porém, a escolha de "unease "se justifica por possibilitar a rima sibilante, e também porque a falta do poético aqui será compensada por uma dicção mais elevada em outros momentos do poema. Podemos dizer, então, que houve uma perda, mas ela será relativamente compensada, com o uso no verso seguinte da palavra "turbulence", de origem latina, e que em inglês ganha um tom mais elevado, além de também preservar a rima sibilante.

"Ilharga", no segundo verso, foi um dos momentos de maior complexidade semântica da tradução. Ilharga, em português, pode significar: 1) os lados dos corpos; 2) os lados de um caixão; 3) os lados de um navio. Além disso, podemos fazer uma leitura do "significante" ilharga, por onde caberia a leitura "ilha" + "larga", que não é despropositada no contexto do poema, onde as palavras "água", "navio" e "transparência" proporcionam uma atmosfera aquática, ou marinha, ao poema. Por enquanto, "lagoon" foi mantido na versão, mas é preciso buscar palavras com sentido de "lado"/ "edge”, e talvez assim seja possível uma melhor correspondência. 
“Dentro da solidão”: em português, “da” é uma contração de “de” + “a”, cuja tradução literal para o inglês ficaria excessiva: “inside of the solitude”. Escolhemos retirar o artigo definido e manter apenas a preposição of, realçando a materialidade da expressão, por isso o uso de "inside of solitude".

No caso de "a dying body”, perdemos a rima, mas ambas as palavras parecem demasiado fortes para serem alteradas.

No verso 5, ocorreu uma mudança sintática e também lexical. “As coisas planejadas” virou "plans and future”, ou seja, “coisas” caiu e "planejadas” virou substantivo. Esta alteração não me pareceu ruim porque manteve uma certa indeterminação presente no português, isto é, não são especificadas quais são as coisas planejadas, ao mesmo tempo em que possibilitou a rima $a$ de “future”. Embora no original uma menção ao futuro não seja explicitada, “coisas planejadas” carrega uma alusão ao futuro, por isso não parece fora de lugar a inclusão dessa palavra.

Já no verso que termina com “a line in mid-air”, perdemos a rima, porém foi a imagem mais próxima que conseguimos para "um fio suspenso", ainda que a materialidade de "fio" seja bem mais forte do que a de "line". Neste caso, podemos falar de uma clara perda semântica.

Curiosamente, a palavra pórtico, do verso 11, tem um equivalente em inglês bastante exato: "portico". Mas talvez a escolha de "portico" em inglês, com sua origem evidentemente latina, elevaria demais o tom do poema, e a palavra portal permite manter uma dicção nobre, mas sem causar tanto estranhamento.

Em nenhum nível foi mantida uma correspondência completa, o que significa, em outras palavras, que a versão não se manteve fiel. Porém, ao preservar uma boa quantidade de rimas, e usando um léxico que parece fazer parte de uma mesma esfera poética, acredito que “this mournful moon” tenha ganhado em inglês uma música e um corpo parecidos com sua existência original.

\section{Poema 2}

(original em português)

Sorrio quando penso

Em que lugar da sala

Guardarás o meu verso

Distanciado

Dos teus livros políticos

Na primeira gaveta

Mais próxima à janela? 
Tu sorris quando lês

Ou te cansas de ver

Tamanha perdição

Amorável centelha

No meu rosto maduro?

E te pareço bela

Ou apenas te pareço

Mais poeta talvez

E menos séria?

O que pensa o homem

Do poeta? Que não há verdade

Na minha embriaguez

E que me preferes

Amiga mais pacífica

E menos aventura?

Que é de todo impossível

Guardar na tua sala

Vestígio passional

Da minha linguagem?

Eu te pareço louca?

Eu te pareço pura?

Eu te pareço moça?

Ou é mesmo verdade

Que nunca me soubeste?

Em termos formais, o mais marcante neste poema são os versos curtos, onde as sílabas 2 e 6 são marcadas em quase todos os versos, quando não a terceira e a sexta sílabas, criando um ritmo preciso e constante (ver anexo 3).

As rimas também estão presentes, embora, nem de longe, tenham neste poema a mesma importância que têm no poema anterior. Ao longo de quase todo o poema temos sons que rimam entre si, como gaveta e centelha, e a rima é completa entre lês, talvez e embriaguez. Nos versos finais, aparecem as rimas toantes pacífica/impossível .

Outra marca importante é a repetição de certas estruturas sintáticas. Quase todo o poema é composto de perguntas, feitas por um "eu” diretamente a um “tu”, e esta marcação sintática (eu-tu) é também constante. A expressão “te pareço”, por sua vez, é repetida cinco vezes.

Apesar de uma estrutura relativamente simples, este poema apresenta algumas questões lexicais que se revelaram bastante complexas no momento de traduzi-las. Nos versos “amiga mais pacífica/ e menos aventura”, aventura passa como adjetivo por causa da terminação feminina, mas ainda assim causa uma estranheza, como uma “agramaticalidade poética”. E nos versos finais: “ou é mesmo verdade/que nunca me soubeste?”, onde “saber” substitui o verbo “conhecer”, mais comum neste contexto. 
Normalmente o verbo "conhecer" é usado quando nos referimos a uma outra pessoa, e "saber”, ao mesmo tempo que é mais inusitado, traz consigo uma conotação de sabor, de algo que se saboreia, e também de algo que se sabe porque se apreende, como algo passível de ser estudado. E ainda, em português, fazemos uma diferença de sentido entre saber e conhecer, que não ocorre em inglês, onde “to know" é usado indistintamente.

Antes de vermos com mais detalhe como foram resolvidas estas questões semânticas, vamos ler o poema em inglês e analisar as correspondências formais.

\author{
Poema 2 \\ (versão em inglês) \\ I smile when I wonder \\ Where in your room \\ You keep my verse. \\ Away from your \\ Political books? \\ In the first drawer \\ Close to the window? \\ Do you smile when you read \\ Or are you tired of seeing \\ Such abandon \\ Amorous spark \\ On my ripened face? \\ Do I seem beautiful \\ Or am I to you \\ Too much of a poet, perhaps, \\ And not serious enough? \\ What does the man think \\ Of the poet? That there's no truth \\ In my drunkenness \\ And that you prefer \\ A friend more peaceful \\ And less adventurous? \\ That you simply cannot \\ Keep in your room \\ Worldly traces \\ Of my passionate words? \\ Do you see me as mad? \\ Do you see me as pure? \\ Do you see me as young? \\ Or is it real \\ That you never knew me?
}


A repetição, umas das principais marcas deste poema, de certa forma facilitou o trabalho do tradutor. E, neste quesito, poderíamos dizer que foi mantido um alto nível de correspondência. As marcas de pessoa também foram quase sempre mantidas.

A presença de dois acentos primários por verso também foi razoavelmente mantida, mas as rimas, por sua vez, se perderam por completo (ver anexo 4).

Mais complexo nesta tradução foi lidar com alguns pontos da semântica. Vejamos alguns itens:

“Tamanha perdição/Amorável centelha”: Para traduzir “perdição”, escolhemos “abandon”, que não parece de todo convincente. E “amorável” talvez tivesse sua tradução mais literal em "lovely”, porém, ao passo que lovely é uma palavra totalmente banal em inglês, o mesmo não pode ser dito de “amorável”. Por isso, escolhemos “amorous”, que em inglês tem um forte sentido de sensualidade, coerente com a poética hilstiana.

"Maduro": Quase impossível de ser traduzido, ao mesmo tempo que não poderia ser omitido. Mature em inglês implica em algo mais moralizante, e este certamente não é o sentido do poema. Por enquanto, escolhemos "ripened", que ao menos aproxima mais a idéia da fruta madura, bonita, pronta para ser comida, algo como o rosto maduro da mulher.

“Amiga mais pacífica/menos aventura”: Como falamos anteriormente, aqui temos uma espécie de "incongruência poética” de difícil tradução. Em inglês, optou-se por manter dois adjetivos, "peaceful” e “adventurous”. Outra idéia, não muito convincente, seria: “A friend more peaceful/and less adventure?”. Ou ainda, poderíamos deslocar o que em português é um estranhamento lexical, para algo sintaticamente inusitado em inglês, como: “A friend peacefully/ and less adventurous?”. Também não parece bom.

Por fim, temos o verso final, e como já falamos acima, o verbo “saber”, ambíguo, com mais de um significado. Não conseguindo encontrar em inglês um vocábulo que concentrasse todas estas nuances, optou-se por jogar a ambigüidade para outro local, para verso anterior. "Or is it real/that you never knew me" é uma construção, no mínimo, estranha, que ao menos abre as possibilidades de leitura do final do poema.

Por mais que se faça uma análise objetiva dos níveis de correspondência, depois de uma longa convivência com os poemas e suas respectivas traduções, é difícil dizer se essas últimas ficaram boas ou não. A leitura de um poema é também algo extremamente 
pessoal e tem sua porção não analisável. Provavelmente vestígios desta leitura são levados à tradução, e nem sempre o tradutor poderá ter consciência destes momentos. A meu ver, só seria possível constatar a eficácia da tradução se nos fosse dado ler "pela primeira vez" o poema em inglês. Seriam os efeitos desta leitura parecidos com os provocados no momento em que ele foi lido pela primeira vez em português? Recuar no tempo é impossível. Traduzir, ao menos, por mais problemático que seja, por mais que perdas sejam inevitáveis, não é tão impossível assim.

\section{Referências}

BRITTO, Paulo H. (2002) "Para uma avaliação mais objetiva das traduções de poesia”. In KRAUSE, Gustavo Bernardo. As Margens da Tradução. Rio de Janeiro: FAPERJ/Caetés/UERJ.

COELHO, Nelly N. (1999) “Da poesia”. In Cadernos de Literatura Brasileira/Hilda Hilst. São Paulo: Instituto Moreira Salles.

HILST, Hilda (2001) Júbilo, Memória, Noviciado da Paixão (organização Alcir Pécora). São Paulo: Globo.

\section{ANEXO 1}

\section{Símbolos:}

| = separador de sílabas

/ = sílaba com acento primário

$\backslash$ = sílaba com acento secundário

- = sílaba átona

I I = pausa

1) Es|sa| lu|a en|lu|ta|da, esse| de|sas|sos|se|go

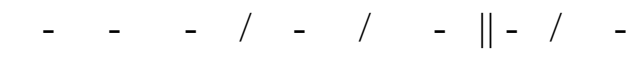


2) A| con|vul|são| de| den|tro|, i|lhar|ga

3) Den|tro| da| so|li|dão|, cor|po| mor|ren|do

$$
1-1-1-1-\| 1-1 / 1-
$$

4) Tu|do| i|sso| te| de|vo. E e|ram| tão| vas|tas

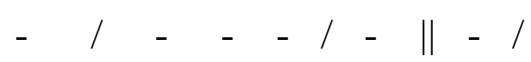

5) As| coi|sas| pla|ne|ja|das|, na|vios,

6) $\mathrm{Mu}|\mathrm{ra}| \mathrm{lhas}|\mathrm{de}|$ mar|fim|, pa|la|vras| lar|gas

7) Con|sen|ti|men|to| sem|pre|. E se|ri | a| de|zem|bro.

8) Um| ca|va|lo| de| ja|de| sob| as| á|guas

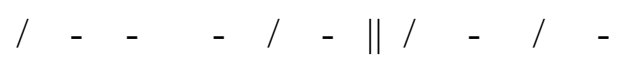

9) Du|pla| trans|pa|rên|cia|, fio| sus|pen|so

$$
1-1-1-||-1--1 / 1-
$$

10) To|das| es|sas| coi|sas| na| pon|ta| dos| teus| de|dos

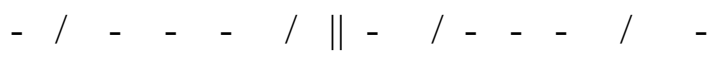

11) E| tu|do |se| des|fez| no| pór|ti|co| do| tem|po 
12) Em| lí|vi|do| si|lên|cio|. U|mas| ma|nhãs| de| vi|dro

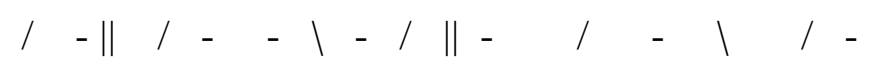

13) Ven|to, a| al|ma| es|va|zi|a|da, um| sol| que| não| ve|jo.

14) Tam $\mid$ bém| is $\mid$ so $\mid$ te $\mid$ de|vo.

Esquema de rimas:
1) b, a
2) a, b
3) $\mathrm{x}, \mathrm{a}$
4) a, b
5) b, c
6) c, b
7) a, a
8) b, b
9) a, a
10) $x, a$
11) a, a
12) a, c
13) a, b, a

14) $b$ 
Aliterações:

No verso 1, lua/enlutada e esse/desassossego.

No verso 4, tudo/te/tão

No verso 6, muralhas/marfim

No verso 7, consentimento/sempre

\section{ANEXO 2}

1) This mournful moon, this unease

$$
1-1-1 \mid-1
$$

2) Inner turbulence, lagoon,

$$
-1-1-1||-1-1-
$$

3) Inside of solitude, a dying body,

$$
\text { | } 1-1-1 \mid-1
$$

4) All this I owe you. Such immense

$$
1-1-\| 1
$$

5) Plans and future, ships,

$$
\text { / }-1-\| 1 /
$$

6) Walls of ivory, words full

$$
1-\quad-1--\|-\quad-1-1-
$$

7) Always consented to. It would be December.

$-11-1-1-$

8) A jade horse beneath the waters

$$
1-\quad-1-\quad-||-\mid-1 / 1
$$

9) Double transparency, a line in mid-air

$$
\text { / } 11 \mid 1--1 \quad-1
$$


10) All these things at your fingertips

11) All undone through the portal of time

$$
\text { | }-\quad-\quad \mid \|-1 \quad-\quad-1
$$

12) Silent and blue. Some mornings of glass,

$$
\text { | }||-|-1| \mid-1-1 \text { | }
$$

13) Wind, a hollow soul, a sun I can't see

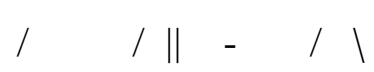

14) This, too, I owe you.

Esquema de rimas (onde $x$ representa a ausência de rima)
1) $\quad a, b$
2) b, a
3) $a, x$
4) a, b
5) $a, x$
6) $x, a$
7) a, b
8) $x, a$
9) $b, x$

10) b, b

11) $x, x$ (obs: through, primeira palavra do segundo hemistíquio, contém o som da rima a)

12) a, b

13) $x, x, b$

14) a, a

\section{Aliterações:}

No verso 1 , mournful/moon.

No verso 7, walls/words

No verso 10, these/things

No verso 12, silent/ some 
No verso 13, soul/sun/see

\section{ANEXO 3}

Sor|rio| quan|do| pen|so $\quad(2,6)$

$-1-1-1-$

Em| que| lu|gar| da| sa|la $\quad(2,4,6)$

Guar|da|rás| o| meu| ver|so $\quad(3,6)$

Dis|tan|cia|do| (3)

Dos| teus| li|vros| po|lí|ti|cos $\quad(3,6)$

$\mathrm{Na}$ | pri|mei|ra| ga|ve|ta

Mais| pró|xi|ma à| ja|ne|la? $\quad(2,6)$

$-\quad 1-\quad-1$

$\mathrm{Tu}$ | sor|ris| quan|do| lês| $\quad(3,6)$ 
Ou| te| can|sas| de| ver|

$(3,6)$

Ta|ma|nha| per|di|ção|

$(2,6)$

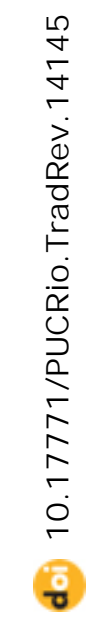

$-\quad 1-\quad-1-$

A|mo|rá|vel| cen|te|lha

$(3,6)$

No| meu| ros|to| ma|du|ro?

$(3,6)$

E| te| pa|re|ço| be|la|

$(4,6)$

Ou a|pe|nas| te| pa|re|ço|

$1-1--1$

Mais| po|e|ta| tal|vez

- 1 - 1 -

E| me|nos| sé|ria?|

O| que| pen|sa| o| ho|mem|

$(3,6)$

Do| po|e|ta? |||Que| não| há| ver|da|de|

$(3,7,9)$ 
$\mathrm{Na}$ mi|nha em|bri|a|guez

$(2,6)$

E| que| me| pre|fe|res|

$(2,5)$

$-1-1-1--$

A|mi|ga| mais| pa|cí|fi|ca

$(2,6)$

$-1---1-$

$(2,6)$

E| me|nos| a|ven|tu|ra?

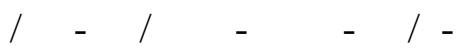

Que é| de| to|do im|pos|sí|vel

Guar|dar| na| tu|a| sa|la

Ves|tí|gio| pas|sio|nal|

$(2,6)$

Da| mi|nha| lin|gua|gem?|

$(2,5)$

$-1-1-1-$

Eu| te| pa|re|ço| lou|ca?|

$(2,6)$ 
$-1-1-1-$

Eu| te| pa|re|ço| pu|ra?|

Eu| te| pa|re|ço| mo|ça?|

$(2,6)$

Ou| é| mes|mo| ver|da|de|

Que| nun|ca| me| sou|bes|te?

$(2,6)$

Rimas:

Versos 1 e 3 (penso, verso)

Versos 6, 8, 9, 11, 15, 19 (gaveta, lês, ver, centelha, talvez. embriaguez)

Versos 21 e 23 (pacífica, impossível)

Versos 26, 28 (louca, moça)

\section{ANEXO 4}

I smile when I wonder

Where in your room

you keep my verse. 
$-1-1$

Away from your

$-1--1$

Political books?

In the first drawer

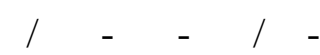

Close to the window?

Do you smile when you read

Or are you tired of seeing

/ - / -

Such abandon

/ - - I

Amorous spark

On my ripened face?

Do I seem beautiful

$-1--1$

Or am I to you

Too much of a poet, perhaps,

And not serious enough?

What does the man think 
Of the poet? That there's no truth

In my drunkenness

And that you prefer

A friend more peaceful

And less adventurous?

That you simply can not

$1-\quad-1$

keep in your room

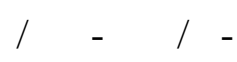

worldly traces

$-\quad-1 \quad-\quad /$

of my passionate words

Do you see me as mad?

$-\quad-1-\quad-1$

Do you see me as pure?

$-\quad 1--1$

Do you see me as young?

Or is it real

That you never knew me? 